\title{
SOEP
}

SOEPpapers

on Multidisciplinary Panel Data Research
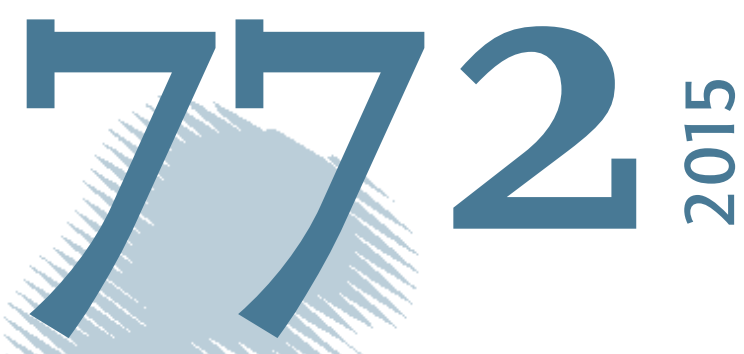

\section{Revisiting the evidence for a cardinal treatment of ordinal variables}

Carsten Schroeder and Shlomo Yitzhaki 
This series presents research findings based either directly on data from the German SocioEconomic Panel study (SOEP) or using SOEP data as part of an internationally comparable data set (e.g. CNEF, ECHP, LIS, LWS, CHER/PACO). SOEP is a truly multidisciplinary household panel study covering a wide range of social and behavioral sciences: economics, sociology, psychology, survey methodology, econometrics and applied statistics, educational science, political science, public health, behavioral genetics, demography, geography, and sport science.

The decision to publish a submission in SOEPpapers is made by a board of editors chosen by the DIW Berlin to represent the wide range of disciplines covered by SOEP. There is no external referee process and papers are either accepted or rejected without revision. Papers appear in this series as works in progress and may also appear elsewhere. They often represent preliminary studies and are circulated to encourage discussion. Citation of such a paper should account for its provisional character. A revised version may be requested from the author directly.

Any opinions expressed in this series are those of the author(s) and not those of DIW Berlin. Research disseminated by DIW Berlin may include views on public policy issues, but the institute itself takes no institutional policy positions.

The SOEPpapers are available at http://www.diw.de/soeppapers

\section{Editors:}

Jan Goebel (Spatial Economics)

Martin Kroh (Political Science, Survey Methodology)

Carsten Schröder (Public Economics)

Jürgen Schupp (Sociology)

Conchita D'Ambrosio (Public Economics)

Denis Gerstorf (Psychology, DIW Research Director)

Elke Holst (Gender Studies, DIW Research Director)

Frauke Kreuter (Survey Methodology, DIW Research Fellow)

Frieder R. Lang (Psychology, DIW Research Fellow)

Jörg-Peter Schräpler (Survey Methodology, DIW Research Fellow)

Thomas Siedler (Empirical Economics)

C. Katharina Spieß (Education and Family Economics)

Gert G. Wagner (Social Sciences)

ISSN: 1864-6689 (online)

German Socio-Economic Panel Study (SOEP)

DIW Berlin

Mohrenstrasse 58

10117 Berlin, Germany

Contact: Uta Rahmann | soeppapers@diw.de 


\title{
Revisiting the evidence for a cardinal treatment of ordinal variables
}

By

Carsten Schroeder ${ }^{* *}$ and Shlomo Yitzhaki ${ }^{*}$

\begin{abstract}
Well-being (i.e., satisfaction, happiness) is a latent variable, impossible to observe directly. Hence, questionnaires ask people to grade their well-being in different life domains. The most common practice-comparing well-being by means of descriptive analysis or linear regressions-ignores that the underlying collected well-being information is ordinal. If the well-being function is ordinal, then monotonic transformations are allowed. We demonstrate that treating ordinal data by methods intended to be used for cardinal data may give an incorrect impression of a robust result. Particularly, we derive the conditions under which the use of cardinal method to an ordinal variable gives an illusionary sense of robustness, while in fact one can reverse the conclusion reached by using an alternative cardinal assumption. The paper provides empirical applications.
\end{abstract}

Keywords: satisfaction, well-being, ordinal, cardinal, dominance

JEL codes: $\mathrm{C} 18, \mathrm{C} 23, \mathrm{C} 25,130,131,139$

\footnotetext{
** DIW Berlin / SOEP and School of Business \& Economics, Free University Berlin, cschroeder@diw.de. *Hebrew University, shlomo.yitzhaki@mail.huji.ac.il. We would like to thank Teresa Backhaus and Christoph Halbmeier for their most helpful research assistance. We would also like to thank Jürgen Schupp and Gert G. Wagner for suggestions on an earlier version of the paper.
} 


\section{Introduction}

There is enormous interest in the social sciences in studying the interrelationships between psychological well-being (i.e., satisfaction, happiness) and socioeconomic outcomes. Initiatives, the most influential one being the Commission sur la Mesure de la Performance Économique et du Progrès Social, even argue in favor of complementing standard sets of economic-performance indicators (GDP, growth and interest rates, etc.) with aggregate wellbeing statistics (Stiglitz et al. 2009 and 2010). Indeed, since 1972, Bhutan is measuring "gross national happiness," with several other countries (e.g., Thailand, Australia, China, France and the United Kingdom) developing comparable indices. The Satisfaction with Life Index (White, 2007) is an attempt to provide aggregate happiness statistics for different nations.

Well-being is a latent variable, impossible to observe directly. On top of that, it does not have a natural quantitative unit, like meters, to measure it. Hence, questionnaires ask people to grade their well-being in different life domains. All over the world, the same type of question is used: "All in all, how satisfied are you with your life (income / health, etc.) at the moment?" Usually, responses are provided on 4 to 11 -point scales. ${ }^{1}$ In empirical analyses, the scale values are aggregated by countries or societal subgroups for well-being rankings, or serve as dependent and independent variables in regressions. The most common practice-that of comparing well-being by means of descriptive analysis or linear regression models-ignores that the obtained information on well-being is ordinal and relies on methods appropriate for quantitative variables. This usage is justified in the literature, with explanations such as, "most subjective well-being measures are technically ordinal, but the evidence suggests that treating them as cardinal does not generally bias the results obtained (Ferrer-i-Carbonell and Frijters, 2004)" (OECD 2013, p. 174). However, the underlying paper merely states, "we find that assuming ordinality or cardinality of happiness scores makes little difference, whilst allowing for fixed-effects does change results substantially" (Ferrer-i-Carbonell and Frijters, 2004, p. 641).

The aforementioned statements rely on comparisons of regression estimates from models, such as OLS, fixed and random effects, that interpret satisfaction scores as cardinal with models, such as ordered logit and probit, that interpret scores as ordinal. For example Ferrer-i-Carbonell and Frijters (2004), hereafter FCF (2004), use responses to the German Socio-economic Panel's question on general life satisfaction, measured on a 11-point scale, and use it as dependent variable in regression models that impose a cardinal or ordinal level of measurement.

In treating the answers of the respondents two major questions arise: (a) whether all respondents interpret the questions in the same way and provide credible information; ${ }^{2}$ and (b) the distance that investigators attribute to the different categories. In this paper, we assume that all respondents interpret the categories in the same way and concentrate on the implication of (b), the effect of quantification of the categories by the investigator. Specifically, we will derive the conditions under which the use of cardinal method to an ordinal variable gives an illusionary sense of a robust result, while in fact one can reverse the conclusion reached by using an alternative cardinal assumption. In other words, we

${ }^{1}$ For interdisciplinary conventions to operationalization of well-being see Diener (2006).

2 Oswald and Wu (2010) scrutinize the meaningfulness of individuals' subjective well-being assessments with an objective measure: spatial compensating differentials, and find a strong state-bystate match between subjective and objective well-being. 
complement the previous research by deriving the conditions that allow answers to the following type of question: Suppose an eleven-point satisfaction scale 1, 2, .., 11 is used as dependent variable in OLS and ordered logit regressions. According to both models money makes people happier. Is there a monotonic increasing transformation of the satisfaction scale such that OLS and ordered logit yield contradictory conclusions? Hence, our conditions are a tool for applied researchers to check if a monotonic transformation of the ordinal variable used reverses the conclusions.

Our conditions are not only relevant in the area of happiness and well-being. Another important application is the measurement of educational achievements and evaluation of education programs with test scores from exams, as collected and compiled by the Programme for International Student Assessment (PISA) of the OECD.

The structure of the paper is as follows. Section 2 provides a literature review focusing on the techniques of analysis used in previous analyses. In Section 3, we present the conditions under which it is possible to reverse the rankings of means of satisfaction among groups and the signs OLS regression coefficients. In Section 4, we provide empirical evidence that one can reverse both rankings and regression coefficients. Section 5 concludes.

\section{Literature Review}

An increasing number of publications address the interrelationships between well-being variables (happiness, standard of living, satisfaction) and socio-economic, health and related outcomes. The total number of published articles listed by IDEAS RePec containing synonyms of "happiness" in the abstract adds up to more than 3,700. Almost 1,000 have been published since 2004, with the number of annual publications increasing to about 200 in 2013 and 2014. Econometric techniques employed to study the interrelations are heterogeneous, encompassing descriptive comparisons of means and medians, as well as various kinds of regression models.

This literature review focuses on the techniques of analysis used in earlier literature. Table A1 in Appendix A1 provides more detailed information on the methods used. More general literature reviews can be found in Frey and Stutzer (2002), Lyubormirsky et al. (2005), Dolan et al. (2008), and Weimann, Knabe and Schöb (2015). See also Kahneman and Krueger (2006), Clark et al. (2008), Powdthavee (2010) and OECD (2013)

A significant number of papers in interdisciplinary journals treat well-being data from surveys as cardinal and make use of OLS regressions and comparisons of average happiness levels. For example, when revisiting the Easterlin paradox (1974), Easterlin et al. (2010) employ OLS regressions to study the dependence of happiness on GDP, showing "that the long term nil relationship between [average] happiness and income holds also for a number of developing countries, the eastern European countries transitioning from socialism to capitalism, and an even wider sample of developed countries than previously studied" [p. 22463] and that "that in the short-term in all three groups of countries, happiness and income go together" [p. 22463]. In a later paper Easterlin et al. (2012) compare averages of different life satisfaction measures to show that "China has followed the life satisfaction trajectory of the central and eastern European transition countries- a U-shaped swing and a nil or declining trend" [p. 9775]. De Neve and Oswald (2012) employ linear regression 
techniques to study if adolescents and young adults who report higher life satisfaction grow up to earn significantly higher levels of income later in life.

The use of cardinal techniques for an ordinal variable is not restricted to interdisciplinary or psychological journals, as can be found in economic journals such as the American Economic Review, Economic Journal, or Journal of Public Economics.

Dynan and Ravina (2007), for example, use OLS regressions to study how peoples' happiness depends on their relative income position within their geographic area. Hetschko et al. (2014) apply linear regression models to study the impact of the transition from unemployment to retirement on life satisfaction (after conditioning on different sets of explanatory variables). They also compare average life-satisfaction levels of unemployed at different stages around retirement to support their findings. In the same line, Ifcher and Zarghamee (2011) investigate if happiness matters for time preferences by using happiness as one of the controls in an OLS regression framework.

There is, of course, also a large literature that considers the ordinal nature of well-being measures by using regression techniques like ordered logit or probit. One of these studies is Blanchflower and Oswald (2004) in the Journal of Public Economics. They support Easterlin's hypothesis by showing that overall reported levels of well-being in the US have declined and life satisfaction has remained flat in Britain. As their empirical basis is cross-sectional, they cannot control for person fixed or random effects. A much-cited study on the macroeconomics of happiness is Di Tella and MacCulloch (2003) in the Review of Economics and Statistics, showing that movements in reported well-being are correlated with changes in macroeconomic variables such as gross domestic product, by using ordered probit and country fixed effects. Another much-cited study by Alesina et al. (2004) finds that individuals have a lower tendency to report themselves happy when inequality is high using ordered logit regressions. FCF (2004) and several follow-up studies use fixed effects ordered models to investigate the determinants of life satisfaction. Specifically, they use person-specific threshold values, which allows controlling for the fact that some people tend to choose among higher values on the happiness scale than others.

Our main point in this paper is that treating ordinal variable by methods that are intended to be used for cardinal methods, may give a false impression of a robust result, while at the same time there is another legitimate transformation of the ordinal variable into a cardinal one that may reverse the conclusion reached.

\section{The Theory}

If a variable is ordinal, it implies that it obeys the rules of stochastic dominance (Levy, 2006). This means that it yields a unique and robust ranking of one distribution over another if and only if the ranking is not affected for all monotonic increasing transformations applied to the ordinal variable. Here it is worth to distinguish between first and second degrees of dominance.

Let us denote the well-being variable by $h$. Assume that we interested to rank average degree of well-being between two groups, call them $b$ (boys) and $g$ (girls). 
First order stochastic dominance (FSD): $E_{b}\{h\} \geq E_{g}\{h\}$ for all $h$, with $h^{\prime}>0$ if and only if the cumulative distribution of $b$ is below or equal the cumulative distribution of $g$ and it is strictly below for at least one observation. If, on the other hand, the cumulative distributions intersect, then it is possible to find two scales of $h$ that will reverse the ordering.

This is shown below:

Let $h(s), f(s)$ represent well-being and its density function among a given sub-population $i$. Well-being, $s$, is continuous but is not observed. Expected well-being is:

$$
E(h)=\int_{0}^{\infty} h(s) f(s) d s .
$$

Integrating equation (1) by parts, with $h(s)=u(s), u^{\prime}(s)=h^{\prime}(s), v^{\prime}(s)=f(s), v(s)=$ $-[1-F(s)]$, where $F(s)$ is the cumulative density function (CDF), we get:

$$
E(h)=-\{h(s)[1-F(s)]\}+\int\left(h^{\prime}(s)[1-F(s)] d s .\right.
$$

The left term on the right-hand side is equal to $h(0)$, so it can be ignored when comparing expected well-being in two groups. Therefore, the only term remaining relevant is the righthand term.

Consider a comparison between groups $b$ and $g$. Expected well-being depends on whether the CDFs intersect, because $h(s)$ is an arbitrary function determined by the scales used by the investigator. Therefore:

$$
E_{b}(h)-E_{g}(h)=\int_{0}^{\infty} h^{\prime}(s)\left[F_{g}(s)-F_{b}(s)\right] d s .
$$

Since $h^{\prime}(s)$ is non-negative and arbitrary, it implies that if the CDFs intersect there is an alternative well-being function that can change the ranking of expected well-being of the two groups in descriptive and regression analysis.

Ranking groups by average scores is performed by the OECD using PISA exams, which will not be discussed in detail in this paper. In the following we focus on the treatment of ordinal variables as cardinal in a regression context. In this respect, second order stochastic dominance is relevant:

Second order stochastic dominance (SSD): $E_{b}\{h\} \geq E_{g}\{h\}$ for all $h$, with $h^{\prime}>0, h^{\prime \prime}<0$ if and only if the absolute Lorenz curve of $b$ is not lower than the absolute Lorenz curve of $g$, and at least for one observation it is strictly above. If, on the other hand, the absolute Lorenz curves of the two groups intersect, then there exist two scales of $h$ that lead to inverse rankings of the two groups. (Atkinson, (1970), proved it for equal-mean distributions; Shorrocks, (1984) extended it to all kinds of distributions).

A slightly different version of the above proposition that deals with the possibility of reversing the sign of a regression coefficient is developed in Yitzhaki and Schechtman (2012, 2013). The proposition relies on an application of concentration curves in the context of regressions, implying the existence of a Line of independence Minus Absolute concentration curve (LMA): ${ }^{3}$

\footnotetext{
${ }^{3}$ A proof can be found in both Yitzhaki and Schechtman (2012) and Yitzhaki and Schechtman (2013,
} pp. 92-97). For convenience, a demonstration is supplied in the Appendix. 
LMA: (Line of independence Minus Absolute concentration curve). If the LMA curve of the dependent variable with respect to the independent variable intersects the horizontal axis, then it is possible to find two monotonic increasing transformations of the independent variable that will result in two negating signs of the OLS regression coefficient.

The LMA curve is the vertical difference between two absolute concentration curves. The absolute concentration curve is similar to the absolute Lorenz curve except that on the vertical axis the cumulative expected conditional values of $Y$ given $X$ is presented. The LMA is the vertical difference between the absolute concentration curve of $Y$ given $X$, under the assumption that the two variables are statistically independent, which is a Line, minus the actual Absolute concentration curve of $Y$ as a function of $F(X)$. An illustrative example of the construction of the LMA curve can be found in the Appendix A2.

There are five properties of the LMA curve:

(a) The LMA curve starts at $(0,0)$ and ends up at $(1,0)$.

(b) The area enclosed between the curve and the horizontal axis is equal to $\operatorname{cov}(Y, F(X))$, which is the equivalent to the classical covariance provided that one uses Gini's Mean Difference as the measure of variability.

(c) If the curve is above (below) the horizontal axis then the contribution of this section to $\operatorname{cov}(Y, F(X))$ is equal to its height (negative height).

(d) If the curve intersects the horizontal axis then there are two monotonic transformations of $X, T_{1}(X)$ and $T_{2}(X)$ : one resulting in $\operatorname{cov}\left(Y, T_{1}(X)\right)>0$, and the other in $\operatorname{cov}\left(Y, T_{2}(X)\right)<0$, meaning that there is a monotonic transformation of $X$ that can change the sign of the OLS regression coefficient of $Y$ on $X$.

(e) Truncation of the curve at a given point and connecting the truncated area by a line then one can evaluate the sign of the covariance (or the local regression coefficient) at this range. This enables evaluating the effect of throwing extreme observations.

To check whether one can reverse the ranking of average scores in comparing two groups by applying a monotonic increasing transformation, one has to check whether the cumulative distributions of the two groups intersect, while checking whether one can change the sign of the simple regression coefficient one has to check whether the LMA curve intersects the horizontal axis.

\section{Empirical Evidence}

In this section we apply the theoretical conditions to the same data used by FCF (2004) in order to examine the robustness of its conclusions. We check whether a monotonic transformation of satisfaction that can change the sign of regression coefficient exists. ${ }^{4}$

${ }^{4}$ An alternative procedure is outlined in Nielsen (2015). He assesses the sensitivity of empirical methods for measuring group differences in achievement based on ordinal data. He defines a distance measure over possible weighting functions to derive a "worst-case bounds for the bias in the estimated achievement gap" (p. 1). 
Before we start, we have to clarify one point relevant for an ordinal variable that is a dependent variable. The LMA rules of Section 2 can be applied only for the independent variables. However, we will use the property of the OLS regression that the sign of the regression coefficient is equal to the sign of the inverse regression. The explanation for this property is that the sign of the regression coefficient in OLS regression is determined by the sign of $\operatorname{cov}(Y, X)$ which is equal to the sign of $\operatorname{cov}(X, Y) .^{5}$

Our empirical database is the German Socio-economic Panel (SOEP), a representative panel of the population living in Germany, with the first data wave collected in 1984. We use the SOEP wave v29, covering the 1984 to 2012 period. Every year, about 20,000 persons in 12,000 households are interviewed. Most importantly for our purposes, the SOEP provides detailed information on individual- and household-level socio-demographics plus satisfaction assessments in several life domains. For detailed information on the data see Wagner et al. (2007).

Our empirical analysis rests on two SOEP-based working samples. The first working sample is constructed along the instructions provided in the Technical Appendix to FCF (2004). It is an unbalanced sample of West-German workers, observed from 1992 through 1997. With it, we explore the robustness of conclusions reached by FCF (2004). The second working sample contains more recent data, covering 1992 through 2012. It is an unbalanced sample without any constraints imposed on employment status or other socioeconomic characteristics. Only persons with missing values in the required variables in a particular year are discarded. With the second sample we demonstrate that ordered logit and probit models indicate a dominance relationship of the cumulative distributions that might not supported by the data. Summary statistics on both working samples appear in Table A3 in Appendix A3.

\subsection{Results from OLS regressions}

We start our empirical analysis with the same two OLS regression specifications as in FCF (2004). The first OLS regression model takes the form,

$$
\begin{aligned}
h_{i, t}= & \alpha+\beta a g e_{i t}+\gamma a g e_{i t}^{2}+\delta \ln \left(y_{i t}\right)+\theta n_{\text {children }, i, t}+\vartheta D_{\text {partner }, i, t}+\mu h_{\text {healt }, i, t} \\
& +\sum_{t=1993}^{1997} \pi_{t} D_{t}+\varepsilon_{i t}
\end{aligned}
$$

The dependent variable is reported overall life satisfaction by respondent $i$ in period $t, h_{i, t}$, measured on an equally-spaced 11-point scale from 0 to 10 . The independent variables are:

1. Age of respondent $i$ in period $t, a g e_{i t}$, and squared age, $a g e_{i t}^{2}$.

2. Log of disposable monthly household income of respondent $i$ in period $t, \ln \left(y_{i t}\right)$

3. Number of children living in household of respondent $i$ in period $t, n_{\text {children,i,t }}$

4. Partner living in respondent $i$ 's household in period $t, D_{\text {partner }, i, t}$; a dummy variable.

5. Satisfaction with health of respondent $i$ in period $t, \mu h_{\text {health,i,t }}$

6. Period dummies for years 1993 to $1997, D_{t}$

5 This symmetry assumption between $\operatorname{cov}(X, Y)$ to $\operatorname{cov}(Y, X) \overline{\text { characterizes the OLS and is not }}$ imposed in Gini regression, Yitzhaki and Schechtman (2013). As shown in Yitzhaki (2015), this assumption alone may cause an unjustified change in the sign of the OLS regression coefficient. 
The second OLS regression model includes an extended set of independent variables,

$$
\begin{aligned}
h_{i, t}= & \alpha+\beta \text { age }_{i t}+\operatorname{\gamma age}_{i t}^{2}+\delta \ln \left(y_{i t}\right)+\theta n_{\text {children }, i, t}+\vartheta D_{\text {partner }, i, t}+\mu h_{\text {healt }, i, t} \\
& +\sum_{t=1993}^{1997} \pi_{t} D_{t}+\rho \text { educ }_{i, t}+\sigma D_{\text {male }, i, t}+\tau n_{\text {adult }, i, t}+\varepsilon_{i t}
\end{aligned}
$$

The additional independent variables include:

1. Education level of respondent $i$ in period $t, e d u c_{i t}$, measured on a 3-point scale.

2. Dummy for male respondents, $D_{\text {male }, i, t}$

3. Number of adults living in household of respondent $i$ in period $t, n_{\text {adults,i,t }}$

The results from both specifications are summarized in the first two columns of Table 1 . The adjacent two columns provide the estimates provided in Table 1 in FCF (2004).

Our regression estimates and those in FCF (2004) are very similar but not identical, perhaps due to the slight difference in the numbers of observations. ${ }^{6}$ For example, the coefficients in both regressions suggest that being rich in income makes your life better, while being rich in children makes it worse.

We now plot the LMA curves. The properties required for analyzing them are the following: On the horizontal axis the cumulative distribution of $X$ is presented. The vertical Axis describes the vertical difference between the cumulative value of $E\{Y \mid F(X)=F(x)\}$ would $Y$ and $X$ be statistically independent minus the actual cumulative value.

The first set of LMA curves in Figure 1a are those that can tell us whether and the properties of a monotonic non-decreasing transformation applied satisfaction can change the sign of a simple OLS regression coefficient. The first LMA curve presented is with respect to age. As shown, the lowest 20 percent of observations of satisfaction create a tiny positive covariance with age. The third curve in the first line presents the LMA of $\ln (Y)$. As can be seen the curve creates a positive covariance between the variables. However, concentrating on high level of satisfaction, we can see a negative covariance. Hence, a transformation that will shrink low level of satisfaction and expand high level is capable of changing the sign of an OLS regression coefficient.

\footnotetext{
${ }^{6}$ We could not reproduce the exact same data, because the exact code used to create the data in CFC (2004) is lost.
} 

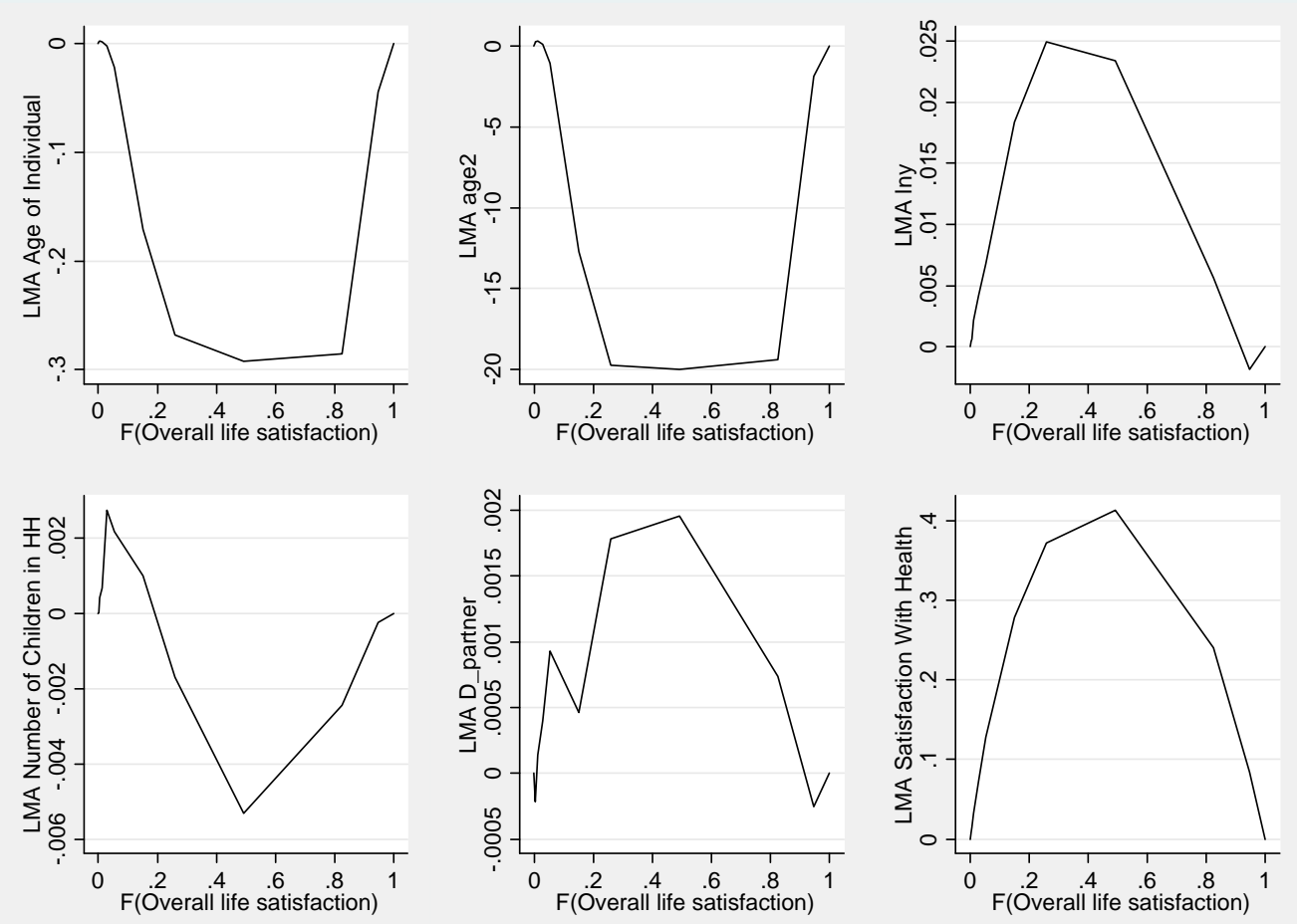

Note. Own estimates. Data is SOEP v29. F denotes cumulative density function.

Figure 1a. LMA of independent variables with respect to satisfaction

The second line of curves presents additional possibilities. Low satisfaction levels create positive covariance with the number of children in the household while high level of satisfaction is associated with negative covariance. The relationship between having a steady partner and satisfaction is not monotonic. Overall it ends up with a positive covariance, but at high levels and in the middle we see sections with negative covariance.

The GMD has two covariances between two variables and they do not have to be with the same sign. They reflect the idea that what you see from here need not be identical to what you see from there. ${ }^{7}$ Therefore, we also present the other side of the coin in Figure $1 \mathrm{~b} .^{8}$ As can be seen there are no monotonic transformations of income, steady partner, satisfaction with health that can change the sign of the correlation between each variable and satisfaction. (With respect to steady partner it is trivial because it is a binary variable). On the other hand, although the association between the number of children and satisfaction is positive, as the number of children increases it becomes negative. Almost a reverse picture portrays the age on satisfaction. Overall, it is negative but as people age, it tends to be associated with greater satisfaction.

\footnotetext{
${ }^{7}$ This phenomenon occurs whenever one uses two variables to describe a change. In this case one has to fix one variable and to allow the other variable to change. It is equivalent to the "index number problem" taught in intermediate economic courses.

${ }^{8}$ Because the LMA of overall life satisfaction and age respectively age squared are identical, only the LMA between overall life satisfaction and age is provided.
} 

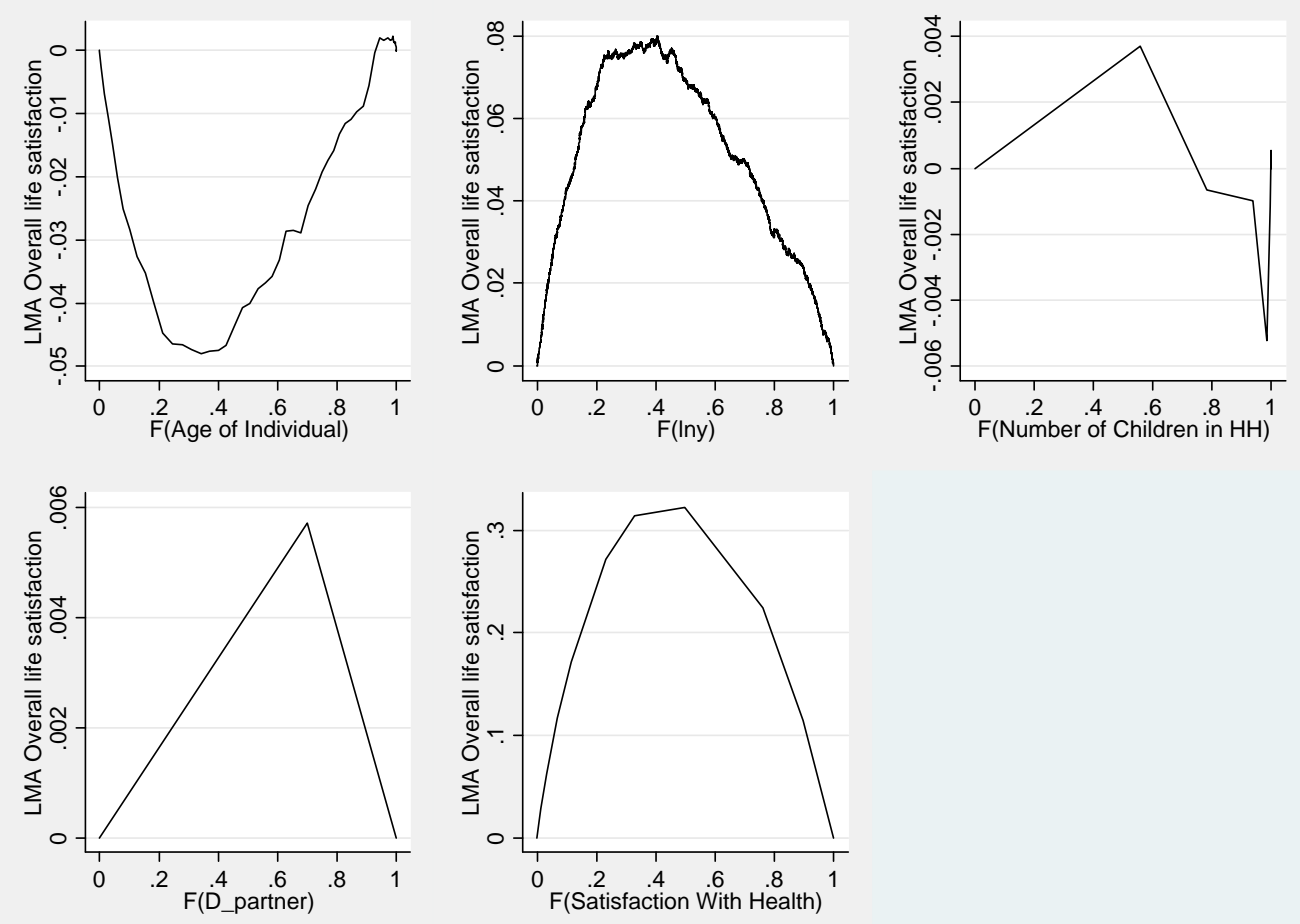

Note. Own estimates. Data is SOEP v29. F denotes cumulative density function.

Figure 1b: The LMAs of Satisfaction with respect to Independent Variables

Having studied the relationship between the variables, we experiment with alternative scales of satisfaction that can change the signs of regression coefficients. Table 2 provides results from OLS regressions a transformation of satisfaction, $\tilde{h}$, that shrinks the differences between low levels of satisfaction (for the exact transformation see first column in Table A4 in Appendix 4). Bold type indicates changes in the sign of regression coefficients due to the transformation. The sign of two regression coefficients have changed. The results of Table 2, in contrast to those of Table 1, suggest that being rich in income makes your life miserable, while being rich in children makes it better.

Finally, it is worth mentioning that the sign changes of Table 2 hold for any linear increasing transformation of the scale that produced the table. Also, the sign changes hold for monotonic increasing transformations that shrink the differences in the scale for the lowest 60 percent of observations of satisfaction, and increase the differences among the 40 percent at the top. An alternative transformation to the one underlying the results in Table 2 that may be viewed as less drastically but also change the sign of the regression coefficients for the log of disposable income are reported in column two of Table A4.

\section{2 [Results from random- and fixed effects linear models}

Random and fixed effects linear models allow researchers to deal with unobserved heterogeneity and rely on weaker assumptions on the inter-personal comparability of 
reported satisfaction scores as standard OLS. However, as standard OLS, these models treat the dependent variable as cardinal, and thus cannot guarantee stability of regression coefficients subject to allowed transformations of $h$. To see this, Table 3 provides a summary of random effect models using the same specifications as in Tables 1 and 2, using both the original and the transformed satisfaction variable, $h$ and $\tilde{h}$, as dependent variables. Table 4 provides the respective estimates from fixed effects.

According to the random effects models and using $h$ as dependent variable, we find that income makes your life better, while children play no role. Using $\tilde{h}$ as dependent variable, income plays no role, while children make it better (at least in specification (1)). According to the fixed-effects models, income makes your life better, while children play no role irrespective of whether one uses $h$ or $\tilde{h}$.

To complete the analysis, Table 5 provides a summary of OLS, fixed-effects and random effects regression estimates for parsimoniously-specified regression model, each considering only one of the independent variables from specification (2), and using as dependent variable either $h$ or $\tilde{h}$. The advantage of this univariate analysis is that reversals of the regression can be uniquely assigned to the transformation of the satisfaction variable as correlations between independent variables are ruled out by definition. For the OLS, we now find contradictory regression coefficients for the log of disposable income, education (but no longer for children). For the fixed-effects model, again significance levels are affected but the sign of the regression coefficient never changes.

To sum up the results from our application, using random-effects does not avoid coefficients reversals. Using fixed-effects avoids reversals but the significance of the coefficients hinges on the transformation. Note, however, that this partially positive message for fixed-effects is not ensured. Reversals of coefficients can easily be demonstrated also for this type of model. $^{9}$

\subsection{Results from ordered logit and probit models}

Many economists are unwilling to interpret satisfaction or happiness scores as cardinal, and thus make use of models of a latent variable form like (ordered logit and probit models) to study the scores' determinants. By construction, such models are immune to monotonic transformations of the dependent variable. However, ordered logit or probit models are not appropriate for checking whether treating an ordinal variable as cardinal changes the conclusions. This is because they result, by definition, in non-intersecting cumulative distributions; i.e., these models assume a dominance relationship of the cumulative distributions that needs not be supported by the data.

To see this, take the ordered logistic model. It builds on the cumulative distribution, $F_{c}(X)=1 /\left(1+e^{-b_{c}+\alpha X}\right)$, where $c=1, \ldots, C$ denotes the cut offs and $\boldsymbol{X}$ is a set of explanatory variables. Assume $\boldsymbol{X}$ contains only a single dichotomous variable, $X=\in(0,1)$, that distinguishes two groups, and $\alpha>0$.

To prove our point we have to show that the CDFs for the two groups do not intersect, i.e., $F(X=1) / F(X=0) \leq 1$ for all $c=1, \ldots, C$.

${ }^{9}$ An example will be provided by the authors upon request. 
Proof via contradiction: Suppose $F(X=1) / F(X=0)>1$

$$
\begin{aligned}
& \Leftrightarrow \frac{1 / e_{c}^{-b+\alpha}}{1 / e_{c}^{-b_{c}}}>1 \\
& \Leftrightarrow e_{c}^{-b}>e_{c}^{-b_{c}+\alpha}
\end{aligned}
$$

The greater sign cannot hold because by assumption we have $\alpha>0$. QED.

The remaining question is if the ordered model indicates significant despite intersecting empirical CDFs, non-intersection of the cumulative distributions of the two groups is justified by the data. The answer is yes. As an illustration, Table 6 summarizes the results from a ordered logit with our standard satisfaction variable $h$ run separately for the SOEP waves 2005 to 2012, looking for satisfaction differences between respondents with German $\left(D_{\text {german }}=1\right)$ and non-German origin $\left(D_{\text {german }}=0\right)$. Underneath the regression results, a column indicates if the empirical CDFs of the two respondent groups do intersect. The dummy variable is significant in five out of eight regressions. In the five significant cases, however, empirical distributions intersect in three cases. Such constellations will not be a rare bird in empirical analyses.

\section{Concluding remarks}

There is enormous interest in the social sciences in studying the interrelationships between psychological well-being and socioeconomic outcomes. The empirical basis for such studies is usually data from surveys, where respondents are asked to state well-being in different life domains, usually on 5 to 11-point scales, with verbal descriptions of well-being attached to scale values. The most common practice-that of comparing well-being by means of descriptive analysis or linear OLS regression models-ignores that the information obtained on well-being is ordinal, meaning that monotonic transformations are allowed.

In the theoretical part of the present paper, we demonstrate that treating ordinal data by methods intended to be used for cardinal data may give a false impression of a robust result. Particularly, we derive the conditions under which the use of cardinal method to an ordinal variable gives an illusionary sense of robustness, while in fact one can reverse the conclusion reached by using an alternative cardinal assumption. To check whether one can reverse the ranking of average scores in comparing two groups by applying a monotonic increasing transformation one has to check whether the cumulative distributions of the two groups intersect, while checking whether one can change the sign of the simple regression coefficient one has to check whether the LMA curve intersects the horizontal axis. In the empirical part, we scrutinize the robustness of the results of a prominent paper on the determinants of satisfaction that is extensively cited by researchers who apply cardinal methods to study ordinal data as it finds consistent results in OLS and logistic regression frameworks. Our empirical analysis, however, shows that admissible transformations of the ordinal satisfaction variable can lead to contradictory results.

The issues discussed in the present paper expanding beyond the measurement of living standards, well-being, and related indicators. Another important application is the measurement of educational achievements and evaluation of education programs with test scores from exams. The issues are also of empirical relevance, not a rare bird: As an 
example, using data from the German Socio-economic Panel (years 2007-12), we have derived cumulative distribution functions of satisfaction in seven life domains for two groups: German and non-German residents. We find 24 intersections in the 42 comparisons. Cumulative density functions of male and female respondents intersect in 41 out of 42 comparisons. As another example, we have performed bi-national comparisons of cumulative distributions from math scores provided in the PISA database from OECD. For 34 OECD countries, in 561 bi-national comparisons cumulative density functions intersect in 273 comparisons. ${ }^{10}$

\section{References}

Alesina, A., Di Tellab, R., and MacCulloch, R.J. (2004): Inequality and Happiness: Are Europeans and Americans Different?, Journal of Public Economics, 88, 2009-2042.

Atkinson, A. B. (1970): On the measurement of inequality, Journal of Economic Theory, 2, 244-263.

Blanchflower, D. G., and Oswald, A. J. (2004): Well-being Over Time in Britain and the USA, Journal of Public Economics, 88, 1359-1386.

Benjamin, D.J., Heffetz, O., Kimball, M.S., and Szembrot, N. (2014): Beyond Happiness and Satisfaction: Toward Well-Being Indices Based on Stated Preference, American Economic Review, 104, 2698-2735.

Clark, A., Frijters, P., and Shields, M.A. (2008): Relative Income, Happiness, and Utility: An Explanation for the Easterlin Paradox and Other Puzzles, Journal of Economic Literature, 46(1), 95-144.

De Neve, J. E., and Oswald, A. J. (2012): Estimating the Influence of Life Satisfaction and Positive Affect on Later Income Using Sibling Fixed Effects, Proceedings of the National Academy of Sciences, 109, 19953-19958.

Diener, Ed (2006): Guidelines for National Indicators of Subjective Well-Being and III-Being, Applied Research in Quality of Life, 1(2), 151-157.

Di Tella, R., MacCulloch, R.J., and Oswald, A. J. (2003): The Macroeconomics of Happiness, Review of Economics and Statistics, 85, 809-827.

Dolan, P., Peasgood, T., and White, M. (2008): Do We Really Know What Makes Us Happy? A Review of the Economic Literature on the Factors Associated with Subjective Well-being, Journal of Economic Psychology, 29, 94-122.

Dynan, K.E., and Ravina, E. (2007): Increasing Income Inequality, External Habits, and SelfReported Happiness, American Economic Review, 97, 226-231.

Easterlin, R.A. (1974): Does Economic Growth Improve the Human Lot? In: David, P.A., and Reder, M.W. (eds.): Nations and Households in Economic Growth: Essays in Honor of Moses Abramovitz, Academic Press: New York, 89-125.

${ }^{10}$ Cumulative distribution functions from math scores are derived by splitting the country-specific populations in 1,000 quantils, considering all five multiply imputed math score variables and bootstrap weights. 
Easterlin, R.A., Morgan, R., Switek, M., \& Wang, F. (2012): China's Life Satisfaction, 19902010, Proceedings of the National Academy of Sciences, 109.25, 9775-9780.

Easterlin, R.A., McVey, L.A., Switek, M., Sawangfa, O., and Smith Zweig, J. (2010): The Happiness-income Paradox Revisited, Proceedings of the National Academy of Sciences 107.52, 22463-22468.

Ferrer-i-Carbonell, A., and Frijters, P. (2004): How Important is Methodology for the Estimates of the Determinants of Happiness?, The Economic Journal, 114, 641-659.

Frey, B. S., and Stutzer, A. (2002): What Can Economists Learn from Happiness Research?, Journal of Economic Literature, 40, 402-435.

Frijters, P., Haisken-DeNew, J.P., and Shields, M.A. (2004): Money Does Matter! Evidence from Increasing Real Income and Life Satisfaction in East Germany Following reunification, American Economic Review, 94, 730-740.

Hetschko, C., Knabe, A., and Schöb, R. (2014): Changing Identity: Retiring from Unemployment, The Economic Journal, 124, 149-166.

Ifcher, J., and Zarghamee, H. (2011): Happiness and Time Preference: The Effect of Positive Affect in a Random-assignment Experiment, 101, The American Economic Review, 31093129.

Kahneman, D., and Krueger, A.B. (2006): Developments in the Measurement of Subjective Well-Being, Journal of Economic Perspectives, 20(1), 3-24.

Kalmijn, W. M., Arends, L. R., and Veenhoven, R. (2011): Happiness Scale Interval Study. Methodological considerations, Social Indicators Research, 102, 497-515.

Levy, H. (2006): Stochastic Dominance, Investment Decision Making under Uncertainty. Second Edition, Springer: New York.

Lyubomirsky, S., King, L., and Diener, E. (2005): The Benefits of Frequent Positive Affect: Does Happiness Lead to Success?, Psychological Bulletin, 131, 803-855.

Nielsen, E.R. (2015). Achievement Gap Estimates and Deviations from Cardinal Comparability, Finance and Economics Discussion Series, 2015-040. Washington: Board of Governors of the Federal Reserve System, http://dx.doi.org/10.17016/FEDS.2015.040.

OECD (2013): Guidelines on Measuring Subjective Well-Being, Paris: OECD.

Oswald, A,J., and Wu, S. (2010): Objective Confirmation of Subjective Measures of Human Well-Being: Evidence from the U.S.A, Science, 327, 576-579.

Powdthavee, N. (2010): The Happiness Equation, London: Icon Books.

Shorrocks, A. F. (1983). Ranking Income Distributions, Economica, 50, 3-17.

Stiglitz, J.E., Sen, A., and Fitoussi, J.-P. (2009): Report by the Commission on the Measurement of Economic Performance and Social Progress. (www.stiglitz-senfitoussi.fr/documents/rapport anglais.pdf).

Stiglitz, J.E., Sen, A., and Fitoussi, J.-P. (2010): Mismeasuring Our Lives: Why GDP Doesn't Add Up, New York - London: The New Press. 
Wagner, G.G., Frick, J.R., and Schupp, J. (2007): The German Socio-Economic Panel Study (SOEP) - Scope, Evolution and Enhancements, Schmollers Jahrbuch, 127(1), 139-169.

Weimann, J., Knabe, A., and Schöb, R. (2015): Measuring Happiness: The Economics of WellBeing, MIT Press: Cambridge, Mass.

White, A. (2007): A Global Projection of Subjective Well-being: A Challenge to Positive Psychology, Psychtalk, 56, 17-20.

Yitzhaki, S., and Schechtman, E. (2012): Identifying Monotonic and Non-monotonic Relationship. Economics Letters, 116, 23-25.

Yitzhaki, S., and Schechtman, E. (2013): The Gini Methodology: A Primer on a Statistical Methodology. Springer: New York. 
Table 1. Estimates from OLS regressions, original dependent variable

\begin{tabular}{|c|c|c|c|c|c|c|}
\hline \multirow{3}{*}{$\begin{array}{r}\text { Dependent variable: } \\
\text { Source: } \\
\text { Specification: }\end{array}$} & \multicolumn{6}{|c|}{$h$} \\
\hline & \multicolumn{4}{|c|}{ our estimates } & \multicolumn{2}{|c|}{ FCF (2004) } \\
\hline & \multicolumn{2}{|c|}{ (1) } & \multicolumn{2}{|c|}{$(2)$} & (1) & (2) \\
\hline age & $-0.033^{* * *}$ & $(0.005)$ & $-0.042^{* * *}$ & $(0.005)$ & -0.03 & -0.05 \\
\hline$a g e^{2}$ & $0.001^{* * *}$ & $(0.000)$ & $0.001^{* * *}$ & (0.000) & 0.0005 & 0.0007 \\
\hline $\ln (y)$ & $0.332^{* * *}$ & $(0.018)$ & $0.411^{* * *}$ & (0.022) & 0.34 & 0.38 \\
\hline$n_{\text {children }}$ & $-0.015^{*}$ & $(0.008)$ & $-0.015^{*}$ & (0.009) & -0.07 & -0.05 \\
\hline$D_{\text {partner }}$ & $0.087^{* * *}$ & $(0.018)$ & $0.063^{* * *}$ & $(0.020)$ & 0.13 & 0.23 \\
\hline$h_{\text {health }}$ & $0.390^{* * *}$ & $(0.004)$ & $0.388^{* * *}$ & $(0.004)$ & 0.54 & 0.39 \\
\hline$D_{1992}$ & 0.000 & (.) & 0.000 & (.) & n.r. & n.r. \\
\hline$D_{1993}$ & $-0.050^{*}$ & $(0.028)$ & $-0.056^{* *}$ & $(0.028)$ & n.r. & n.r. \\
\hline$D_{1994}$ & $-0.086^{* * *}$ & $(0.028)$ & $-0.097^{* * *}$ & (0.028) & n.r. & n.r. \\
\hline$D_{1995}$ & $-0.133^{* * *}$ & $(0.027)$ & $-0.145^{* * *}$ & (0.027) & n.r. & n.r. \\
\hline$D_{1996}$ & $-0.099^{* * *}$ & $(0.028)$ & $-0.114^{* * *}$ & $(0.028)$ & n.r. & n.r. \\
\hline$D_{1997}$ & $-0.247^{* * *}$ & $(0.028)$ & $-0.264^{* * *}$ & $(0.028)$ & n.r. & n.r. \\
\hline educ & & & 0.020 & $(0.013)$ & & n.r. \\
\hline work_hrs & & & $-0.004^{* * *}$ & (0.001) & & n.r. \\
\hline$D_{\text {male }}$ & & & 0.017 & $(0.020)$ & & n.r. \\
\hline$n_{\text {adults }}$ & & & $-0.070^{* * *}$ & (0.011) & & n.r. \\
\hline constant & $2.192^{* * *}$ & $(0.169)$ & $1.990^{* * *}$ & $(0.178)$ & & n.r. \\
\hline $\mathrm{N}$ & 31228 & & 31228 & & 30569 & 30569 \\
\hline $\mathrm{F}$ & 963.415 & & 712.926 & & $\mathrm{nr}$ & $\mathrm{nr}$ \\
\hline r2 & 0.253 & & 0.255 & & 0.25 & 0.26 \\
\hline
\end{tabular}

Note. $h$ denotes original SOEP overall life satisfaction variable, $\tilde{h}$ denotes transformed satisfaction. Standard errors in parentheses. ${ }^{*} p<0.1, * * p<0.05, * * * p<0.01$.

Data: SOEP v29. 
Table 2. Estimates from OLS regressions, transformed dependent variable

\begin{tabular}{|c|c|c|c|c|}
\hline \multirow{2}{*}{$\begin{array}{r}\text { Dependent variable: } \\
\text { Specification: }\end{array}$} & \multicolumn{4}{|c|}{$\tilde{h}$} \\
\hline & \multicolumn{2}{|c|}{ (1) } & \multicolumn{2}{|c|}{ (2) } \\
\hline age & $-0.023^{* * *}$ & $(0.003)$ & -0.018 **** & $(0.003)$ \\
\hline$a g e^{2}$ & $0.000^{* * *}$ & $(0.000)$ & $0.000^{* * *}$ & $(0.000)$ \\
\hline $\ln (y)$ & $-0.050^{* * *}$ & $(0.011)$ & $-0.038^{* * *}$ & $(0.014)$ \\
\hline$n_{\text {children }}$ & $0.011^{* *}$ & (0.005) & 0.007 & $(0.005)$ \\
\hline$D_{\text {partner }}$ & $0.029^{* * *}$ & $(0.011)$ & $0.024^{*}$ & $(0.013)$ \\
\hline$h_{\text {health }}$ & $0.082^{* * *}$ & $(0.002)$ & $0.083^{* * *}$ & $(0.002)$ \\
\hline$D_{1992}$ & 0.000 & (.) & 0.000 & (.) \\
\hline$D_{1993}$ & 0.014 & $(0.017)$ & 0.014 & $(0.017)$ \\
\hline$D_{1994}$ & 0.003 & $(0.017)$ & 0.005 & $(0.017)$ \\
\hline$D_{1995}$ & -0.024 & $(0.017)$ & -0.020 & $(0.017)$ \\
\hline$D_{1996}$ & $-0.038^{* *}$ & $(0.017)$ & $-0.034^{*}$ & $(0.017)$ \\
\hline$D_{1997}$ & $-0.067^{* * *}$ & (0.017) & $-0.062^{* * *}$ & $(0.017)$ \\
\hline educ & & & $-0.052^{* * *}$ & $(0.008)$ \\
\hline work_hrs & & & 0.000 & $(0.000)$ \\
\hline$\overline{D_{\text {male }}}$ & & & -0.003 & $(0.012)$ \\
\hline$n_{\text {adults }}$ & & & 0.001 & $(0.007)$ \\
\hline constant & $4.503^{* * *}$ & $(0.105)$ & $4.398^{* * *}$ & $(0.111)$ \\
\hline $\mathrm{N}$ & 31228.000 & & 31228.000 & \\
\hline $\mathrm{F}$ & 112.147 & & 85.400 & \\
\hline$r_{2}$ & 0.038 & & 0.039 & \\
\hline
\end{tabular}

$h$ denotes original satisfaction variable, $\tilde{h}$ denotes transforme satisfaction. Standard errors in parentheses. ${ }^{*} p<0.1,{ }^{* *} p<0.05$, ${ }^{* * *} p<0.01$. Data: SOEP v29. 
Table 3. Estimates from random-effects model

\begin{tabular}{|c|c|c|c|c|c|c|c|c|}
\hline \multirow{3}{*}{$\begin{array}{r}\begin{array}{r}\text { Dependent variable: } \\
\text { Specification: }\end{array} \\
\text { age }\end{array}$} & \multicolumn{4}{|c|}{$h$} & \multicolumn{4}{|c|}{$\tilde{h}$} \\
\hline & \multicolumn{2}{|c|}{ (1) } & \multicolumn{2}{|c|}{ (2) } & \multicolumn{2}{|c|}{ (1) } & \multicolumn{2}{|c|}{ (2) } \\
\hline & $-0.036^{* * *}$ & $(0.006)$ & $-0.047^{* * *}$ & $(0.007)$ & $-0.025^{* * *}$ & $(0.004)$ & $-0.021^{* * *}$ & $(0.004)$ \\
\hline$a g e^{2}$ & $0.001^{* * *}$ & $(0.000)$ & $0.001^{* * *}$ & $(0.000)$ & $0.000^{* * *}$ & $(0.000)$ & $0.000^{* * *}$ & $(0.000)$ \\
\hline $\ln (y)$ & $0.288^{* * *}$ & $(0.021)$ & $0.366^{* * *}$ & $(0.025)$ & -0.018 & $(0.013)$ & -0.006 & (0.016) \\
\hline$n_{\text {children }}$ & -0.007 & $(0.011)$ & -0.009 & $(0.011)$ & $0.014^{* *}$ & $(0.007)$ & 0.011 & (0.007) \\
\hline$D_{\text {partner }}$ & $0.085^{* * *}$ & $(0.026)$ & $0.065^{* *}$ & $(0.029)$ & $0.030^{*}$ & $(0.016)$ & 0.024 & $(0.018)$ \\
\hline$h_{\text {health }}$ & $0.300^{* * *}$ & $(0.004)$ & $0.300^{* * *}$ & $(0.004)$ & $0.063^{* * *}$ & $(0.003)$ & $0.063^{* * *}$ & $(0.003)$ \\
\hline$D_{1992}$ & 0.000 & (.) & 0.000 & (.) & 0.000 & (.) & 0.000 & (.) \\
\hline$D_{1993}$ & $-0.070^{* * *}$ & $(0.022)$ & $-0.076^{* * *}$ & $(0.022)$ & 0.009 & $(0.015)$ & 0.009 & $(0.015)$ \\
\hline$D_{1994}$ & $-0.119^{* * *}$ & $(0.023)$ & $-0.130^{* * *}$ & $(0.023)$ & -0.005 & $(0.015)$ & -0.005 & (0.015) \\
\hline$D_{1995}$ & $-0.162^{* * *}$ & $(0.023)$ & $-0.174^{* * *}$ & $(0.023)$ & $-0.028^{*}$ & $(0.015)$ & $-0.027^{*}$ & (0.015) \\
\hline$D_{1996}$ & $-0.138^{* * *}$ & $(0.023)$ & $-0.153^{* * *}$ & $(0.023)$ & $-0.047^{* * *}$ & $(0.015)$ & $-0.045^{* * *}$ & (0.015) \\
\hline$D_{1997}$ & $-0.295^{* * *}$ & $(0.023)$ & $-0.312^{* * *}$ & $(0.023)$ & $-0.079^{* * *}$ & $(0.015)$ & $-0.077^{* * *}$ & (0.015) \\
\hline educ & & & $0.040^{* *}$ & (0.019) & & & $-0.050^{* * *}$ & $(0.012)$ \\
\hline work_hrs & & & $-0.002^{* * *}$ & $(0.001)$ & & & -0.000 & $(0.001)$ \\
\hline$D_{\text {male }}$ & & & 0.005 & $(0.029)$ & & & -0.003 & (0.018) \\
\hline$n_{\text {adults }}$ & & & $-0.076^{* * * *}$ & $(0.013)$ & & & -0.004 & (0.008) \\
\hline constant & $3.323^{* * *}$ & $(0.208)$ & $3.090^{* * *}$ & $(0.216)$ & $4.434^{* * *}$ & $(0.130)$ & $4.360^{* * *}$ & (0.135) \\
\hline$N$ & 31228.000 & & 31228.000 & & 31228.000 & & 31228.000 & \\
\hline$\chi^{2}$ & 5661.010 & & 5727.330 & & 658.759 & & 679.863 & \\
\hline$R^{2}$ & 0.252 & & 0.254 & & 0.037 & & 0.039 & \\
\hline
\end{tabular}

Note. $h$ denotes original satisfaction variable, $\tilde{h}$ denotes transformed satisfaction. Standard errors in parentheses.

${ }^{*} p<0.1,{ }^{* *} p<0.05,{ }^{* * *} p<0.01$. Data: SOEP v29. 
Table 4. Estimates from fixed-effects model

\begin{tabular}{|c|c|c|c|c|c|c|c|c|}
\hline \multirow{3}{*}{$\begin{array}{r}\begin{array}{r}\text { Dependent variable: } \\
\text { Specification: }\end{array} \\
\text { age }\end{array}$} & \multicolumn{4}{|c|}{$h$} & \multicolumn{4}{|c|}{$\tilde{h}$} \\
\hline & \multicolumn{2}{|c|}{ (1) } & \multicolumn{2}{|c|}{ (2) } & \multicolumn{2}{|c|}{ (1) } & \multicolumn{2}{|c|}{ (2) } \\
\hline & $-0.047^{*}$ & $(0.016)$ & $-0.058^{* * *}$ & $(0.016)$ & $-0.034^{* * *}$ & $(0.010)$ & $-0.036^{* * *}$ & $(0.011)$ \\
\hline$a g e^{2}$ & -0.000 & $(0.000)$ & -0.000 & $(0.000)$ & 0.000 & $(0.000)$ & 0.000 & $(0.000)$ \\
\hline $\ln (y)$ & $0.183^{* * *}$ & $(0.030)$ & $0.264^{* * *}$ & $(0.035)$ & $0.035^{*}$ & $(0.020)$ & $0.045^{*}$ & $(0.023)$ \\
\hline$n_{\text {children }}$ & 0.015 & $(0.020)$ & -0.004 & $(0.021)$ & 0.008 & $(0.013)$ & 0.006 & $(0.014)$ \\
\hline$D_{\text {partner }}$ & -0.052 & $(0.074)$ & -0.056 & $(0.074)$ & -0.013 & $(0.049)$ & -0.014 & $(0.049)$ \\
\hline$h_{\text {health }}$ & $0.216^{* * *}$ & $(0.005)$ & $0.216^{* * *}$ & $(0.005)$ & $0.040^{* * *}$ & $(0.003)$ & $0.040^{* * *}$ & (0.003) \\
\hline$D_{1992}$ & 0.000 & (.) & 0.000 & (.) & 0.000 & (.) & 0.000 & (.) \\
\hline$D_{1993}$ & -0.020 & $(0.021)$ & -0.023 & $(0.021)$ & 0.020 & $(0.014)$ & 0.020 & $(0.014)$ \\
\hline$D_{1994}$ & -0.016 & $(0.020)$ & -0.019 & $(0.020)$ & 0.018 & $(0.013)$ & 0.018 & $(0.013)$ \\
\hline$D_{1995}$ & 0.016 & $(0.020)$ & 0.015 & $(0.020)$ & 0.020 & $(0.013)$ & 0.020 & $(0.013)$ \\
\hline$D_{1996}$ & $0.096^{* * *}$ & $(0.021)$ & $0.095^{* * *}$ & $(0.021)$ & 0.014 & $(0.014)$ & 0.013 & (0.014) \\
\hline$D_{1997}$ & 0.000 & (.) & 0.000 & (.) & 0.000 & (.) & 0.000 & (.) \\
\hline educ & & & 0.030 & $(0.060)$ & & & 0.010 & (0.039) \\
\hline work_hrs & & & -0.001 & $(0.001)$ & & & -0.001 & $(0.001)$ \\
\hline$D_{\text {male }}$ & & & 0.000 & (.) & & & 0.000 & (.) \\
\hline$n_{\text {adults }}$ & & & $-0.081_{* * *}^{* * *}$ & $(0.019)$ & & & -0.009 & $(0.013)$ \\
\hline constant & $6.411^{* * *}$ & $(0.395)$ & $6.210^{* * *}$ & $(0.399)$ & $4.737^{* * *}$ & $(0.260)$ & $4.721^{* * *}$ & $(0.262)$ \\
\hline$N$ & 31228.000 & & 31228.000 & & 31228.000 & & 31228.000 & \\
\hline$F$ & 218.156 & & 169.396 & & 22.578 & & 17.452 & \\
\hline$R^{2}$ & 0.068 & & 0.066 & & 0.005 & & 0.005 & \\
\hline
\end{tabular}

Note. $h$ denotes original satisfaction variable, $\tilde{h}$ denotes transformed satisfaction. Standard errors in parentheses.

${ }^{*} p<0.1,{ }^{* *} p<0.05,{ }^{* * *} p<0.01$. Data: SOEP v29. 
Table 5. Estimates from univariate regressions

\begin{tabular}{|c|c|c|c|c|c|c|c|c|c|c|c|c|}
\hline \multirow{2}{*}{$\begin{array}{r}\text { Model: } \\
\text { Dependent variable: }\end{array}$} & \multicolumn{4}{|c|}{ OLS } & \multicolumn{4}{|c|}{ Fixed effects } & \multicolumn{4}{|c|}{ Random effects } \\
\hline & \multicolumn{2}{|c|}{$h$} & \multicolumn{2}{|c|}{$\tilde{h}$} & \multicolumn{2}{|c|}{$h$} & \multicolumn{2}{|c|}{$\tilde{h}$} & \multicolumn{2}{|c|}{$h$} & \multicolumn{2}{|c|}{$\bar{h}$} \\
\hline 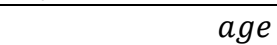 & $-0.008^{* *}$ & $(0.001)$ & $-0.001^{*}$ & $(0.000)$ & $079^{* * * *}$ & $(0.004)$ & $.025^{* * *}$ & $(0.003)$ & $.012^{* *}$ & $(0.001)$ & $.002^{* *}$ & $(0.001)$ \\
\hline$a g e^{2}$ & $-0.000^{* * *}$ & $(0.0$ & -0.000 & $(0.000)$ & $-0.001^{* * *}$ & $(0.000)$ & $-0.000^{* * *}$ & $(0.000)$ & $\mathrm{Do}^{* * *}$ & $(0.000)$ & $-0.000^{* *}$ & $(0.000)$ \\
\hline $\ln (y)$ & 0.39 & $(0.020)$ & $-0.035^{* * *}$ & $(0.0$ & 0 & & & & $0.262^{* *}$ & & & \\
\hline$n_{\text {children }}$ & -0.003 & $(0.009)$ & $-0 .($ & ) & $1^{* * *}$ & & & & 13 & & & (0.007) \\
\hline$D_{\text {partner }}$ & 0.027 & $(0.020)$ & -0.005 & (0.011) & 0.060 & $(0.0$ & 0.025 & (0. & 0.045 & $(0$. & 0.002 & $(0.016)$ \\
\hline$h_{\text {health }}$ & $0.382^{* * *}$ & $(0.004)$ & $0.079^{* * *}$ & $(0.0$ & $0.225^{* * *}$ & $(0.0$ & $0.043^{* * *}$ & $(0.0$ & $0.299^{* * *}$ & $10 . c$ & $0.062^{* * *}$ & (0.003) \\
\hline & 0.1 & (0. & $-0.059^{* * *}$ & & $6^{* *}$ & & $64^{*}$ & & $0.071^{* * *}$ & & $3^{* * *}$ & \\
\hline$r k \_h r s$ & $-0.002^{* * *}$ & $(0.001)$ & -0.001 & $(0.0$ & 2 & $(0.001)$ & 01 & $(0.001)$ & $-0.002^{* *}$ & $(0.0$ & -0.001 & (0.001) \\
\hline$D_{\text {male }}$ & $0.036^{*}$ & $(0.019)$ & -0.000 & (0.010) & 0.000 & (.) & 0.000 & (.) & 0.013 & $(0.030)$ & -0.005 & $(0.016)$ \\
\hline$n_{\text {adults }}$ & $0.077^{* * *}$ & $(0.010)$ & $0.013^{* *}$ & $(0.005)$ & 0.015 & $(0.017)$ & 0.012 & $(0.010)$ & $0.046^{* * *}$ & $(0.012)$ & $0.012^{*}$ & $(0.007)$ \\
\hline
\end{tabular}

Note. $h$ denotes original satisfaction variable, $\tilde{h}$ denotes transformed satisfaction. Standard errors in parentheses. ${ }^{*} p<0.1,{ }^{* *} p<0.05,{ }^{* * *} p<0.01$. Data: SOEP v29. 
Table 6: Estimates from univariate ordered logit regression and empirical cumulative distributions

\begin{tabular}{|c|c|c|c|c|c|c|c|c|c|c|c|c|c|c|c|c|}
\hline & 2005 & & 2006 & & 2007 & & 2008 & & 2009 & & 2010 & & 2011 & & 2012 & \\
\hline$D_{\text {German }}$ & $0.298^{* * *}$ & $(0.049)$ & $0.284^{* * *}$ & $(0.050)$ & $0.248^{* * *}$ & $(0.052)$ & $0.220^{* * * *}$ & $(0.057)$ & $0.153^{* \pi * t}$ & $(0.057)$ & 0.094 & $(0.061)$ & 0.037 & $(0.064)$ & -0.039 & $(0.062)$ \\
\hline $\begin{array}{r}\text { cut1 } \\
\text { cons }\end{array}$ & $-5.128^{* * *}$ & $(0.115)$ & $-5.069^{* * *}$ & $(0.109)$ & $-5.389^{* * *}$ & $(0.128)$ & $-5.396^{* * *}$ & $(0.132)$ & $-5.558^{* * *}$ & $(0.134)$ & $-5.799^{* * *}$ & $(0.153)$ & $-5.794^{* * *}$ & $(0.152)$ & $-5.988^{* * *}$ & $(0.155)$ \\
\hline $\begin{array}{r}\text { cut2 } \\
\text { cons }\end{array}$ & $-4.343^{* * *}$ & $(0.085)$ & $-4.386^{* * *}$ & $(0.084)$ & $-4.502^{* * *}$ & $(0.090)$ & $-4.608^{* * *}$ & $(0.098)$ & $-4.713^{* * *}$ & $(0.097)$ & $-4.919^{* * *}$ & $(0.108)$ & $-4.881^{* * *}$ & $(0.107)$ & $-5.055^{* * *}$ & $(0.108)$ \\
\hline $\begin{array}{r}\text { cut3 } \\
\text { cons }\end{array}$ & $-3.359^{* * *}$ & $(0.063)$ & $-3.487^{* * *}$ & $(0.065)$ & $-3.500^{* * *}$ & $(0.068)$ & $-3.633^{* * *}$ & $(0.074)$ & $-3.729^{* * *}$ & $(0.073)$ & $-3.760^{* * *}$ & $(0.078)$ & $-3.987^{* * *}$ & $(0.083)$ & $-4.142^{* * *}$ & $(0.082)$ \\
\hline $\begin{array}{r}\text { cut4 } \\
\text { cons } \\
\end{array}$ & $-2.544^{* * *}$ & $(0.054)$ & $-2.644^{* * *}$ & $(0.055)$ & $-2.692^{* * *}$ & $(0.058)$ & $-2.777^{* * *}$ & $(0.063)$ & $-2.849^{* * *}$ & $(0.063)$ & $-2.951^{* * *}$ & $(0.068)$ & $-3.065^{* * *}$ & $(0.071)$ & $-3.237^{* * *}$ & $(0.070)$ \\
\hline $\begin{array}{r}\text { cut5 } \\
\text { cons }\end{array}$ & $-1.984^{* * *}$ & $(0.051)$ & $-2.035^{* * *}$ & $(0.052)$ & $-2.107^{* * *}$ & $(0.055)$ & $-2.193^{* * *}$ & $(0.060)$ & $-2.228^{* * *}$ & $(0.059)$ & $-2.397^{* * *}$ & $(0.064)$ & $-2.428^{* * *}$ & $(0.067)$ & $-2.553^{* * *}$ & $(0.065)$ \\
\hline $\begin{array}{r}\text { cut6 } \\
\text { cons }\end{array}$ & $-1.025^{* * *}$ & $(0.048)$ & $-1.042^{* * *}$ & $(0.049)$ & $-1.120^{* * *}$ & $(0.052)$ & $-1.201^{* * *}$ & $(0.057)$ & $-1.206^{* * *}$ & $(0.056)$ & $-1.414^{* * *}$ & $(0.061)$ & $-1.369^{* * *}$ & $(0.064)$ & $-1.540^{* * *}$ & $(0.062)$ \\
\hline $\begin{array}{r}\text { cut7 } \\
\text { cons } \\
\end{array}$ & $-0.464^{* * *}$ & $(0.048)$ & $-0.426^{* * *}$ & $(0.048)$ & $-0.509^{* * *}$ & $(0.051)$ & $-0.589^{* * *}$ & $(0.056)$ & $-0.609^{* * *}$ & $(0.056)$ & $-0.843^{* * *}$ & $(0.060)$ & $-0.776^{* * *}$ & $(0.063)$ & $-0.953^{* * *}$ & $(0.061)$ \\
\hline $\begin{array}{r}\text { cut8 } \\
\text { cons }\end{array}$ & $0.435^{* * *}$ & $(0.048)$ & $0.496^{* * *}$ & $(0.048)$ & $0.425^{* * *}$ & $(0.051)$ & $0.357^{* * *}$ & $(0.056)$ & $0.316^{* * *}$ & $(0.056)$ & 0.095 & $(0.060)$ & $0.166^{* * *}$ & $(0.063)$ & -0.010 & $(0.061)$ \\
\hline $\begin{array}{r}\text { cut9 } \\
\text { cons } \\
\end{array}$ & $1.967^{* * *}$ & $(0.050)$ & $2.042^{* * *}$ & $(0.051)$ & $1.970^{* * *}$ & $(0.053)$ & $1.961^{* * *}$ & $(0.058)$ & $1.847^{* * *}$ & $(0.057)$ & $1.628^{* * *}$ & $(0.061)$ & $1.721^{* * *}$ & $(0.064)$ & $1.489^{* * *}$ & $(0.062)$ \\
\hline $\begin{array}{r}\text { cut10 } \\
\text { cons }\end{array}$ & $3.449^{* * *}$ & $(0.058)$ & $3.439^{* * *}$ & $(0.058)$ & $3.540^{* * *}$ & $(0.063)$ & $3.461^{* * *}$ & $(0.066)$ & $3.161^{* * *}$ & $(0.064)$ & $3.183^{* * *}$ & $(0.068)$ & $3.213^{* * *}$ & $(0.072)$ & $2.958^{* * *}$ & $(0.068)$ \\
\hline $\begin{array}{r}N \\
\chi^{2} \\
\end{array}$ & $\begin{array}{l}19819 \\
36.950\end{array}$ & & $\begin{array}{l}21211 \\
32.815\end{array}$ & & $\begin{array}{l}19940 \\
22.300\end{array}$ & & $\begin{array}{l}18767 \\
14.864\end{array}$ & & $\begin{array}{l}19839 \\
7.263 \\
\end{array}$ & & $\begin{array}{l}18080 \\
2.397\end{array}$ & & $\begin{array}{c}17734 \\
0.341 \\
\end{array}$ & & $\begin{array}{c}18869 \\
0.390 \\
\end{array}$ & \\
\hline Intersection empirical CDFs & no & & no & & yes & & yes & & yes & & yes & & yes & & yes & \\
\hline
\end{tabular}

Note. $D_{\text {German }}$ is a dummy indicating German nationality. Standard errors in parentheses. ${ }^{*} p<0.1,^{* *} p<0.05,{ }^{* * *} p<0.01$. Data: SOEP v29. 


\section{Appendices}

\section{Appendix A1 - Literature review}

Table A1. Statistical analysis used in previous research on happiness, satisfaction, and wellbeing

\begin{tabular}{|c|c|c|c|c|}
\hline \multirow[b]{2}{*}{ Authors } & \multirow[b]{2}{*}{ Research question } & \multicolumn{3}{|c|}{ Type of statistical analysis } \\
\hline & & $\begin{array}{l}\text { Linear } \\
\text { regression } \\
\text { models }\end{array}$ & $\begin{array}{l}\text { Ordered } \\
\text { logit or } \\
\text { probit }\end{array}$ & Others techniques \\
\hline Alesina et al. (2004) & $\begin{array}{r}\text { Relationship between } \\
\text { inequality and happiness in } \\
\text { Europe and US }\end{array}$ & & Yes & \\
\hline Anger et al.(2009) & $\begin{array}{r}\text { Health and happiness among } \\
\text { Older Adults }\end{array}$ & & & $\begin{array}{r}\text { Comparisons of means } \\
\text { and medians; logistic } \\
\text { regression }\end{array}$ \\
\hline $\begin{array}{l}\text { Benjamin et al. } \\
\text { (2014) }\end{array}$ & $\begin{array}{r}\text { Determinants of happiness and } \\
\text { satisfaction }\end{array}$ & Yes & & \\
\hline $\begin{array}{l}\text { Blanchflower and } \\
\text { Oswald (2008) }\end{array}$ & $\begin{array}{r}\text { Hypertension and happiness in } \\
\text { international perspective }\end{array}$ & Yes & Yes & \\
\hline Blanchflower and & Well-being over time in UK and & Yes & Yes & \\
\hline Oswald (2004) & US & & & \\
\hline $\begin{array}{l}\text { De Neve, Oswald } \\
\text { (2012) }\end{array}$ & $\begin{array}{l}\text { Effect of life satisfaction and } \\
\text { positive affect on later income }\end{array}$ & Yes & & Correlations \\
\hline Di Tella et al. (2003) & $\begin{array}{r}\text { Macroeconomics movements } \\
\text { and happiness }\end{array}$ & & Yes & \\
\hline $\begin{array}{l}\text { Di Tella, } \\
\text { MacCulloch(2006) }\end{array}$ & $\begin{array}{r}\text { Uses of happiness data in } \\
\text { economics }\end{array}$ & Yes & & Comparisons of means \\
\hline $\begin{array}{l}\text { Dynan and Ravina } \\
\text { (2007) }\end{array}$ & $\begin{array}{r}\text { Income inequality, external } \\
\text { habits, and happiness }\end{array}$ & Yes & & \\
\hline $\begin{array}{l}\text { Easterlin et al. } \\
(2010)\end{array}$ & $\begin{array}{r}\text { Relationship between income } \\
\text { and happiness }\end{array}$ & Yes & & Comparisons of means \\
\hline $\begin{array}{l}\text { Easterlin et al. } \\
(2012)\end{array}$ & $\begin{array}{l}\text { Inter-temporal changes of } \\
\text { satisfaction in China compared } \\
\text { in a cross-country comparison }\end{array}$ & & & Comparisons of means \\
\hline Frijters et al. (2004) & $\begin{array}{l}\text { Relationship between real } \\
\text { income and life satisfaction }\end{array}$ & & Yes & $\begin{array}{r}\text { Causal decomposition } \\
\text { analysis }\end{array}$ \\
\hline $\begin{array}{l}\text { Hills, P., \& Argyle, M. } \\
\text { (2001) }\end{array}$ & $\begin{array}{r}\text { Relationship between } \\
\text { introversion, extraversion and } \\
\text { happiness introverts }\end{array}$ & Yes & & \\
\hline $\begin{array}{l}\text { Hetschko et al. } \\
\text { (2014) }\end{array}$ & $\begin{array}{r}\text { Impact of transition from } \\
\text { unemployment to retirement } \\
\text { on satisfaction }\end{array}$ & Yes & & Comparisons of means \\
\hline Luttmer (2005) & $\begin{array}{r}\text { Relative earnings and well- } \\
\text { being }\end{array}$ & Yes & Yes & \\
\hline Ott (2010) & $\begin{array}{l}\text { Relationship between } \\
\text { governance and happiness }\end{array}$ & & & $\begin{array}{r}\text { Correlations based on } \\
\text { average values, } \\
\text { comparisons of means }\end{array}$ \\
\hline Ram (2008) & $\begin{array}{r}\text { Relationship between } \\
\text { government spending and } \\
\text { happiness }\end{array}$ & Yes & & \\
\hline Senik 2014 & $\begin{array}{r}\text { Relationship between wealth } \\
\text { and happiness }\end{array}$ & & & Comparisons of means \\
\hline $\begin{array}{l}\text { Rehdanz, Maddison } \\
\text { (2005) }\end{array}$ & $\begin{array}{r}\text { Relationship between climate } \\
\text { and happiness }\end{array}$ & Yes & & Comparison of means \\
\hline $\begin{array}{l}\text { Veenhoven, Hagerty } \\
\text { (2006) }\end{array}$ & $\begin{array}{r}\text { Relationship between } \\
\text { happiness and (average) } \\
\text { income across nations }\end{array}$ & Yes & & Comparison of means \\
\hline Veenhoven (2003) & $\begin{array}{r}\text { Relationship between } \\
\text { hedonism and happiness }\end{array}$ & & & Comparison of means \\
\hline
\end{tabular}




\section{Appendix A2 - Construction of LMA curves}

In the present example, there is one dependent variable, $x$, and two independent variables, $y_{1}$ and $y_{2}$, together with a frequency weight, $w$.

$F(x)$ is the cumulative distribution of the dependent variable considering the frequency weight.

$A C C\left(y_{1}\right)$ is the absolute concentration curve of the independent variable $y_{1}$. It is the cumulated products of $y_{1}$ and $w$ divided by the sum of weights.

$\operatorname{LoI}\left(y_{1}\right)$ is the line of independence for $y_{1}$, i.e., the product of the weighted mean of $y_{1}$ times $F(x)$.

$\operatorname{LMA}\left(y_{1}\right)$ is the difference of $\operatorname{LoI}\left(y_{1}\right)$ and $\operatorname{ACC}\left(y_{1}\right)$.

Table A2. Construction of LMA curves

\begin{tabular}{ccccccccccc}
$x$ & $y_{1}$ & $y_{2}$ & $w$ & $F(x)$ & $A C C\left(y_{1}\right)$ & $L o I\left(y_{1}\right)$ & $L M A\left(y_{1}\right)$ & $A C C\left(y_{2}\right)$ & $L o I\left(y_{2}\right)$ & $L M A\left(y_{2}\right)$ \\
\hline 1 & 1 & 1 & 1 & 0.077 & 0.077 & 0.633 & 0.556 & 0.077 & 0.343 & 0.266 \\
2 & 2 & 3 & 2 & 0.231 & 0.385 & 1.899 & 1.515 & 0.538 & 1.030 & 0.491 \\
3 & 4 & 4 & 1 & 0.308 & 0.692 & 2.533 & 1.840 & 0.846 & 1.373 & 0.527 \\
3 & 8 & 6 & 2 & 0.462 & 1.923 & 3.799 & 1.876 & 1.769 & 2.059 & 0.290 \\
4 & 9 & 8 & 1 & 0.538 & 2.615 & 4.432 & 1.817 & 2.385 & 2.402 & 0.018 \\
5 & 10 & 6 & 3 & 0.769 & 4.923 & 6.331 & 1.408 & 3.769 & 3.432 & -0.337 \\
6 & 13 & 4 & 1 & 0.846 & 5.923 & 6.964 & 1.041 & 4.077 & 3.775 & -0.302 \\
7 & 14 & 3 & 1 & 0.923 & 7.000 & 7.598 & 0.598 & 4.308 & 4.118 & -0.189 \\
8 & 16 & 2 & 1 & 1.000 & 8.231 & 8.231 & 0.000 & 4.462 & 4.462 & 0.000 \\
\hline
\end{tabular}

Note. Own calculations for hypothetical data.

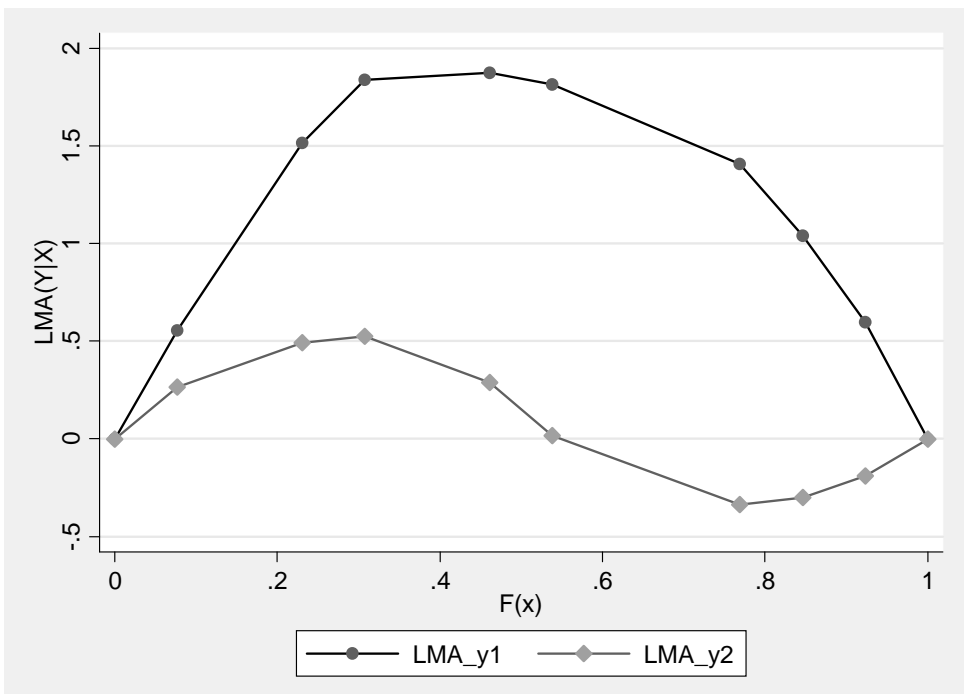

Note. LMA curves from Table A2.

Figure A1. Graphical illustration of LMA curves 
Appendix A3-Empirical analysis

Table A3. Breakdown working sample 1 (FICF (2004)) and sample 2

\begin{tabular}{|c|c|c|c|c|c|c|c|}
\hline Sample & Variable & Akronym & $\mathrm{N}$ & $\min$ & mean & sd & $\max$ \\
\hline \multirow[t]{11}{*}{1 - FICF (2004) } & Satisfaction with overall life & $h$ & 31228 & 0 & 7.216 & 1.630 & 10 \\
\hline & Age & age & 31228 & 16 & 38.316 & 11.737 & 86 \\
\hline & Age squared & $a g e^{2}$ & 31228 & 256 & 1605.906 & 944.560 & 7396 \\
\hline & Log of monthly disposable income & $\ln (y)$ & 31228 & 4.406 & 8.477 & 0.466 & 11.054 \\
\hline & Number of children & $n_{\text {children }}$ & 31228 & 0 & 0.741 & 1.003 & 10 \\
\hline & Dummy partner & $D_{\text {partner }}$ & 31228 & 0 & 0.300 & 0.458 & 1 \\
\hline & Satisfaction with health & $h_{\text {health }}$ & 31228 & 0 & 7.052 & 2.0749 & 10 \\
\hline & Education level & educ & 31228 & 1 & 1.872 & 0.671 & 3 \\
\hline & Working hours per week & work_hrs & 31228 & 0.1 & 38.576 & 11.584 & 80 \\
\hline & Male & $D_{\text {male }}$ & 31228 & 0 & 0.589 & 0.492 & 1 \\
\hline & Number of adults & $n_{\text {adults }}$ & 31228 & 0 & 2.372 & 0.946 & 9 \\
\hline \multirow[t]{2}{*}{2} & Satisfaction with overall life & $h$ & 154259 & 0 & 6.988 & 1.772 & 10 \\
\hline & German nationality & $D_{\text {German }}$ & 154259 & 0 & 0.944 & 0.231 & 1 \\
\hline
\end{tabular}

Note. Data: SOEP, | †ย் 
Appendix A4 - Satisfaction transformations

Table A4. Transformed values of satisfaction

\begin{tabular}{ccc}
$\begin{array}{c}\text { Satisfaction, } \\
h\end{array}$ & $\begin{array}{c}\text { Transformed } \\
\text { satisfaction, } \tilde{h}\end{array}$ & $\begin{array}{c}\text { Alternative } \\
\text { transformation }\end{array}$ \\
\hline 0 & 4.04 & 0 \\
1 & 4.05 & 1 \\
2 & 4.06 & 2 \\
3 & 4.07 & 3.5 \\
4 & 4.075 & 4 \\
5 & 4.08 & 4.25 \\
6 & 4.09 & 4.5 \\
7 & 4.1 & 4.75 \\
8 & 5 & 5 \\
9 & 8 & 8 \\
10 & 8.1 & 10 \\
\hline
\end{tabular}

